\title{
EMA Fault Detection Using Fuzzy Inference Tools
}

\author{
Jordi Cusidó i Roura, Miguel Delgado Prieto, Jose Luis Romeral Martínez \\ MCIA Group, Technical University of Catalonia \\ Spain
}

\section{Introduction}

The challenge in aircraft power system architecture is to move towards the electric power aircraft subsystems including flight control actuation, environmental control system, and utility functions. In this context emerged the concept of "More Electrical Aircraft", which is continuously supported by the new advances in power electronics, electrical motors, digital control and communications.

Traditionally, for primary flight control surfaces only rotary and linear electro-hydraulic actuators (EHA) have been considered, however the later trend is to replace them by electro mechanical actuators (EMA). An EMA has no internal hydraulic fluid, instead using electric motors to directly drive the ram through a mechanical gearbox. Compared to an EHA, the EMA has certain advantages. There is a new issue related to the aforesaid new trend with the aim of improve system reliability. This is the fault detection and diagnosis of the failures that may take place in both, mechanics and electric components. So, it is well assumed that the safety is the main issue for the EMAs development. The motor failures, the damaged bearings, and the eccentricities existing in the drive train, affects on one hand the air gap flux distribution and on the other leads to current and voltage unbalances. However, it is difficult to examine EMA faults by analysing only specific fault harmonics due to fault signal complexity.

To ensure Airplane operation every system needs to be tested and have an associated a Test Program Set (TPS) System. A lot of work has been done in field of TPS and System Design ensuring the testability of a component [1]-[2]. Design for Testability is a major trend in the world of Aerospace and Defence. This paper presents approaches for an one-board fault detection system and TPS fault detection system for EMA by means of Fuzzy Inference Tool.

\section{Presented application}

The solution to monitor the condition of electric motor ball bearings with distributed fault proposed in this work is based in problem analysis from a multivariable point of view, what is to say the obtaining of a fault level result from the combined analysis of different signals with the use of fuzzy logic inference techniques. This is proposed to achieve a reinforced diagnose that will be more effective when it comes to detect bearing failure than using just a single signal, especially when it comes to damage severity evaluation. 


\section{Basic theory}

\section{A. Vibration analysis}

Vibration analysis is one of the most extended condition monitoring techniques [4]. Despite being a reliable, well studied robust technique, one of its drawbacks is that it requires that the motor under test has a vibration transducer installed, condition that makes its online application expensive. In this work its study is set out as a reference for the other techniques without this kind of restriction.

Vibration frequency components related to specific faults - inner ( $\left.f_{\text {irf }}\right)$, outer $\left(f_{\text {orf }}\right)$ and ball $\left(f_{b s f}\right)$ faults - can be calculated using the following expressions [2][4]:

$$
\begin{gathered}
f_{\text {irf }}=\frac{n}{2} \cdot f_{r} \cdot\left[1+\frac{b d}{p d} \cdot \cos \beta\right] \\
f_{\text {orf }}=\frac{n}{2} \cdot f_{r} \cdot\left[1-\frac{b d}{p d} \cdot \cos \beta\right] \\
f_{b s f}=\frac{f_{r}}{2} \cdot \frac{p d}{b d}\left[1-\left(\frac{b d}{p d} \cdot \cos \beta\right)^{2}\right]
\end{gathered}
$$

With:
n: number of balls
$\mathrm{f}_{\mathrm{r}}$ : rotor speed
bd: ball diameter
pd: bearing pitch diameter
$\beta$ : contact angle of the ball on the race

B. As some works and standards [5] [6] [7] set out, a RMS vibration value evaluation of the motor also provides a good indicator for motor health, allowing machine overall fault diagnosis - Stator currents

Stator currents analysis (MCSA) represents an interesting alternative method with its own particularities and benefits; the most interesting of them is sparing the access inside the motor making it easy to perform its online fault analysis.

Previous works have shown the existing correlation between vibration and currents RMS values [5]. Although it is a complex function that relates both magnitudes, this work tries to check the RMS currents reliability in order to perform the motor status diagnose.

With this knowledge, it is possible to execute an RMS calculation over the acquired current signals with the aim of performing a more precise and straightforward operation.

\section{High frequency common-mode pulses}

One of the biggest culprits for bearings failure are common-mode circulating currents, which are generated by switching inverters and expose the motor terminals to high $\mathrm{dv} / \mathrm{dt}$. This phenomenon has been widely exposed in [6] and [7].

In this experiment, to limit the acquired signal to only pulses flowing through bearings (the responsible of balls degradation), a motor modification was introduced. All the ball bearing under test were aisled from the motor stator frame but in a point connected to ground 
through a cable where the pulses were measured. Bearings insulation was achieved by surrounding the piece with a PTFE flat ring with a hole mechanized in it to let the cable pass through.

These currents typically show a frequency range of about $5 \mathrm{MHz}$ with a typical period of 20 $\mu$ setween bursts.

\section{Acoustic emissions}

The Acoustic Emission Technique (AET) is a very promising tool that has practical application in several fields and specifically recent important relevance in condition monitoring of machines. [8] [9] [10]

Acoustic emissions (AE) are high frequency elastic waves in the ultrasound range that appear when a material suffers localised plastic deformation. The analysis of this stress waves shows the nature of the original producing source and, therefore, enables the diagnose conducting to the actual element fault type and severity. In the bearings field, $\mathrm{AE}$ is a good tool to detect impulsive faults like wear, ball impacts and lubrication problems (like contaminants or degradation).

Acoustic Emission is therefore defined as a radiation of mechanical elastic waves produced by the dynamic local rearrangement of the material internal structure. This phenomenon is associated with cracking, leaking and other physical processes and was described for the first time by Josef Kaiser in 1950. He described the fact that no relevant acoustic emission was detected until the pressure applied over the material under test surpassed the previously highest level applied.

Acoustic Emissions Technique is classified as a passive technique because the object under test generates the sound and the Acoustic Emission sensor captures it. By contrast, Active methods rely on signal injection into the system and analysis of variations of the injected signal due to system interaction.

Then an acoustic emission sensor captures the transient elastic waves produced by cracking or interaction between two surfaces in relative motion and converts their mechanical displacement into an electrical signal. This waves travel through the material in longitudinal, transverse (shear) or surface (Rayleigh) waves, but the majority of sensors are calibrated to receive longitudinal waves.

Wherever the crack is placed, the signal generated travels from the point of fracture to the surface of the material. The transmission pattern will be affected by the type of material crossed and then isotropic material will lead to spherical wave front types of propagation only affected by material surfaces or changes, where the Snell law rules their reflection and reflexion. On Figures 1 and 2 is shown the evolution of acoustic waves inside a Material. On Figure 2 it is shown how appear reflections on waves due to the defect.

The biggest advantage of this method is probably that it is capable of detecting the earliest cracks of the system and their posterior growth, making possible fault detection before any other current method. The main drawback is that it requires additional transducers and a well controlled environment. 


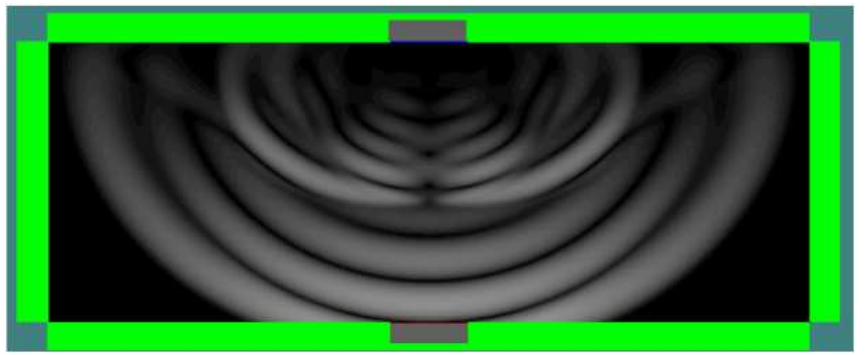

Fig. 1. Acoustic Emission Wave Propagation

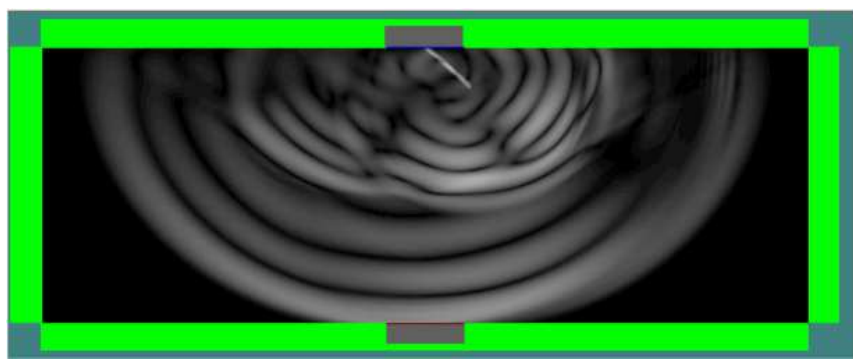

Fig. 2. Acoustic Emission Wave Propagation in fractured Material

\section{Bearing measurements and analysis}

The hertzian contact stresses between the rolling elements and the races are one of the basic mechanisms that initiate a localized defect. Faults in bearings mainly appear in races and balls. Damages in the bearing races are due to metal fatigue and consequent plastic limit variation. Singular ball defects include cracks, pits, and spalls on the rolling surfaces, at it is shown on Figure 3.

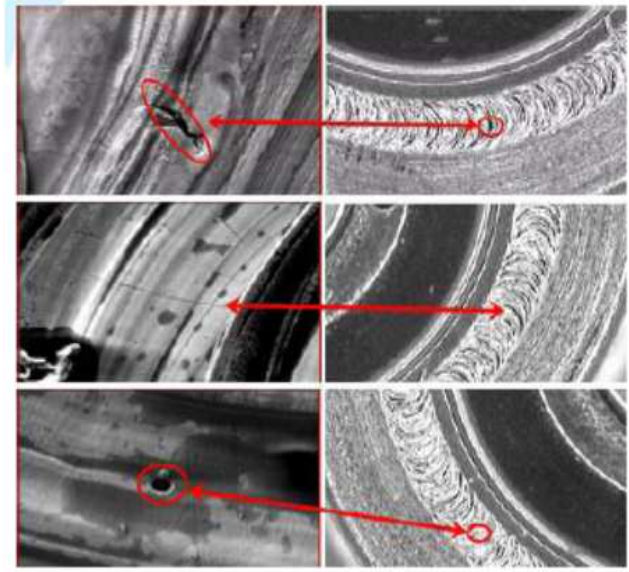

Fig. 3. Bearing Damage Evolution 
Bearing race damage is characterized firstly by changes of metal characteristics like elastic limit and later by the appearance of pits and transverse flutes burnt into the bearing race. Bearing race defects lead to changes in high frequency resonance of the metal. Singular defects in rolling element give rise to isolated impacts as the defective surface hits another surface and produces a single detectable AE pulse. Frequency and periodicity of the pulses are related to material characteristics and rotating speed, and are also depending on the type of bearing.

A number of signal processing methods have been used on the time domain to diagnose failures by AE measurements in machinery [13]-[14]. Although these methods are quite simple to apply, it is apparent that they involve a significant expertise in the interpretation of the output [15]. As a conclusion, and despite lubrication and some bearing faults are detectable in the time domain analysis, to benefit most from the high sensitivity of AE to defects filtering and reconstruction from time - frequency transforms are proposed in this project, as a way to diagnose the bursts and apply time - frequency analysis to perform the feature extraction and characterise the faults. If mean or overall AE parameters obtained from characterisation are considered as fault detection parameters, they can be most suited as a trending parameter where its current value is to be compared to previous ones under similar operational conditions; however more detailed investigations are still required for applying AE for prognosis.

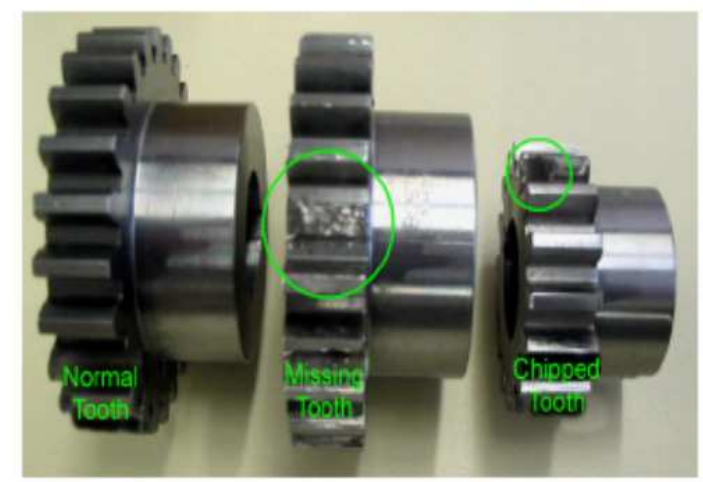

Fig. 4. Main defects on Gears

\section{Gear boxes measurements and analysis}

Whilst vibration analysis on gear fault diagnosis is well established, gearboxes are inevitably more complex to monitor using vibration analysis as they contain various shaft support bearings rotating at different speeds and a number of gear teeth interactions which again are operating at different speeds.

Fatigue tests were carried out and they showed that AE detected the first sign of failure when the gear reached $90 \%$ of its final life. As the crack progressed, AE amplitude increased. During the final stage of gear tooth fracture, a significantly high amplitude AE burst was detected. On the other hand, the vibration level did not change significantly in the initial stage of crack initiation and propagation until the final stage of failure [16]. 
As alternative to these vibration monitoring techniques, AE measurements can be made and then do further analyses by using different signal processing techniques, such as cumulative energy count [17], monitoring of rms, standard deviation and duration of AE [18], and kurtosis analysis [19].

Wavelet transforms have been also used for fault diagnosis of gears [20]. By this technique, the time domain AE signals of a rotating machine with normal and defective gears can be processed through wavelet transform to decompose in terms of low-frequency and highfrequency components. The extracted features from the wavelet transform were used as inputs to an artificial - intelligence based diagnostic approach. From these experiments, it is concluded that $\mathrm{AE}$ method offered an advantage over vibration monitoring techniques, especially for rubbing faults at a low speed. However, difficulty in understanding AE signals, complexity in related signal processing and a lack of industrial development have hampered the manufacture and large scale use of these kind of sensors.

\section{Experimental results}

\subsection{Experimental setup}

In order to assess the effectiveness of the methodology proposed in this work, it has been checked by means of experimental data obtained from a motor bench.

The experimental motor bench is based on two identical featured face to face motors, the motor under test and the motor that acts as a load. Between the motors it has been added an screw and a mobile part which is displaced over it. The screw as well as the mobile part has been provided by SKF. The motors are two SPMSMs with 3 pairs of poles, rated torque of $2.3 \mathrm{Nm}, 230 \mathrm{Vac}$, and rated speed of $6000 \mathrm{rpm}$ provided by ABB Group. The motor under test was driven also by an ABB power converter model ACSM1. The drive control for the motor was a vector control, with speed control loop.

The measurement equipment is focused on the acquisition of a stator current, stator common mode currents, vibration and acoustic emissions. The stator currents have been measured by means of a Tektronix current probe model A622. It provides 10-100 mV/A output and can measure ac/dc currents from $50 \mathrm{~mA}$ to 100 A-peak over a frequency range from dc to $100 \mathrm{kHz}$. The stator currents have been acquired by means a PXIe 1062 system from National Instruments sampling at $50 \mathrm{kHz}, 100 \mathrm{~ms}$ for each measurement.

The vibration measurement has been performed by an ENDEVCO Isotron KS943B.100 triaxial accelerometer with IEPE (Integrated Electronics Piezo Electric) standard output and linear frequency response from $0.5 \mathrm{~Hz}$ to $22 \mathrm{kHz}$ with a maximum of $60 \mathrm{~g}$. The acceleration data was collected using a specific acquitsition card connected to the PXIe 1062 system from National Instruments sampling at 20kS/s, 10 seconds for each measurement.

\subsection{Experimental results}

\section{A. Vibrations}

With regard to the bearings units under test, there was a healthy one (with very similar vibration levels to other new units tested in previous works) and the other two tested units had different levels of damage due their operation hours, qualitatively evaluated with a shock pulse tester from SPM Instruments. 


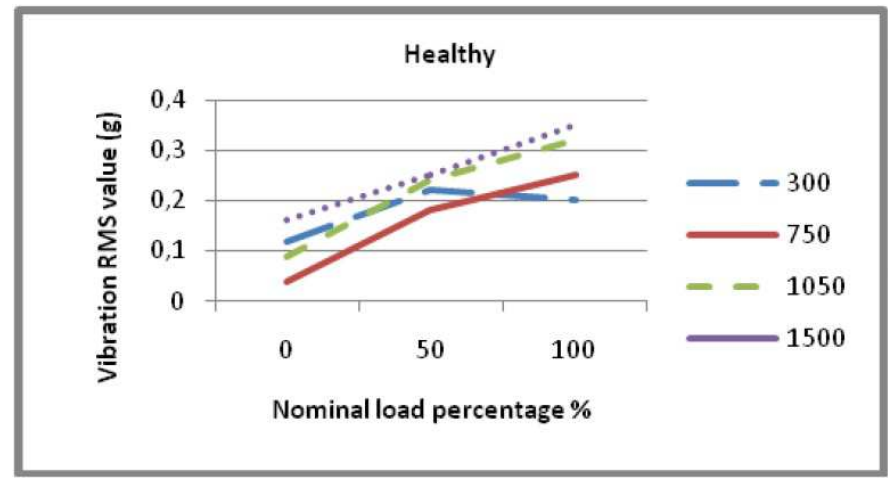

Fig. 5. RMS Vibration for healthy unit, all speeds in rpm and loads.

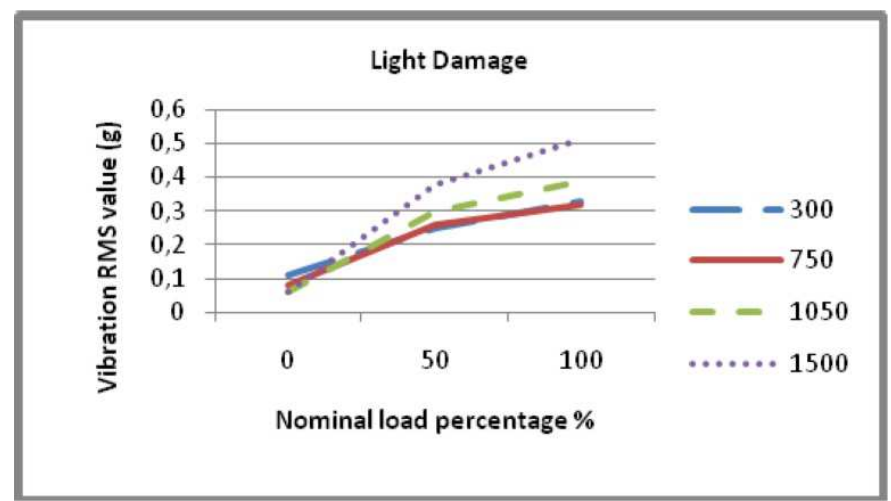

Fig. 6. RMS Vibration for lightly damaged unit, all speeds in rpm and loads.

Fig. 5, 6 and 7 show the evolution of the RMS value of each motor vibration for all speeds and load values tested. The healthy unit shows lower values especially detectable under nominal conditions.

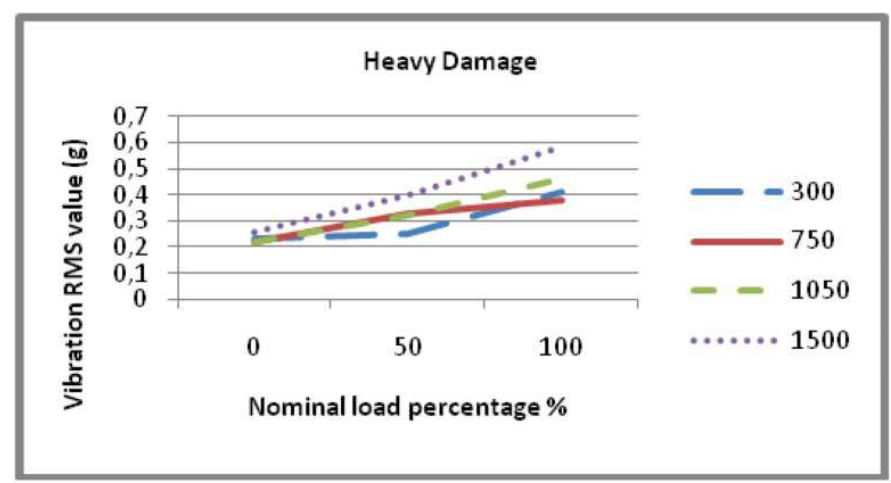

Fig. 7. RMS Vibration for heavily damaged unit, all speeds in rpm and loads. 
Clearly, the healthy motor in Fig. 5 shows lower RMS values of vibration in comparison to the other two units. Fig. 7 unit data, which was in the worst operational condition according to the SPM measurements performed, gave also the highest levels of RMS vibration values.

\section{B. Stator currents}

To avoid the influence of the main harmonic power value in the RMS measurement, signals have been previously filtered using a band-rejection 5th order Butterworth filter centred in the power supply main harmonic with a bandwidth of $20 \mathrm{~Hz}$ between higher and lower cutoff frequencies. Tables 1 and 2 compare the RMS filtered values of the heavily and lightly damaged units with the healthy one.

\begin{tabular}{|r|r|r|r|r|}
\hline \multicolumn{6}{|l|}{ Heavily Damaged-Healthy (A RMS) } \\
\hline Load \% \speed & 300 & 750 & 1050 & 1500 \\
\hline 0 & 0,004 & $-0,006$ & $-0,008$ & $-0,007$ \\
\hline 50 & 0,036 & 0,03 & 0,073 & 0,044 \\
\hline 100 & 0,018 & 0,026 & 0,024 & 0,024 \\
\hline
\end{tabular}

Table 1. Difference in RMS filtered current value between heavily damaged unit and healthy one used as reference.

\begin{tabular}{|r|r|r|r|r|}
\hline \multicolumn{6}{|l|}{ Lightly Damaged-Healthy (A RMS) } \\
\hline Load \% \speed & 300 & 750 & 1050 & 1500 \\
\hline 0 & 0,008 & 0,002 & $-0,003$ & $-0,003$ \\
\hline 50 & 0,002 & $-0,011$ & $-0,002$ & $-0,005$ \\
\hline 100 & 0,02 & 0,012 & 0,003 & 0,014 \\
\hline
\end{tabular}

Table 2. Difference in RMS filtered current value between lightly damaged unit and healthy one used as reference.

A significant difference can be clearly appreciated when the motor is heavily damaged under load condition. Light damage is noticeable under nominal load conditions but its detection does not seem to be easily reliable.

\section{B. High Frequency bearings pulses}

Bearings pulses threshold analysis has been executed to validate theories of correlation between bearings state (wear, lubrication, distributed defects, etc.) and pulses discharge over a threshold value.

The results summarized in Figure 8 show that over a defined threshold level healthy bearings undergo a bigger number in comparison to the damaged units. It is noticeable also that this method is able to detect failure at its initial stage if the threshold is correctly placed.

\section{Acoustic emission testing}

Acoustic Emission acquired data has been statistically classified by means of value binning tools and histogram presentation.

Fifteen sets of data were acquired for each motor and averaged. Fig. 5 shows the results comparing the RMS voltage values acquired for the different units under test. 


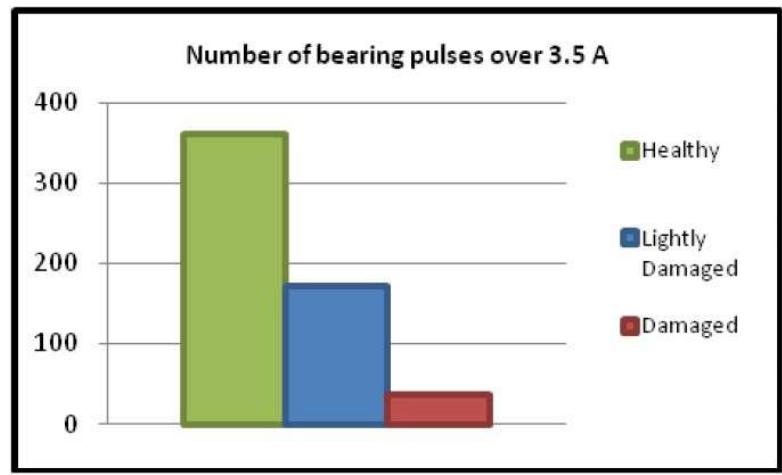

Fig. 8. Number of bearing pulses over threshold value of $3.5 \mathrm{~A}$ for all motors under test. Healthy, lightly damaged and heavily damaged.

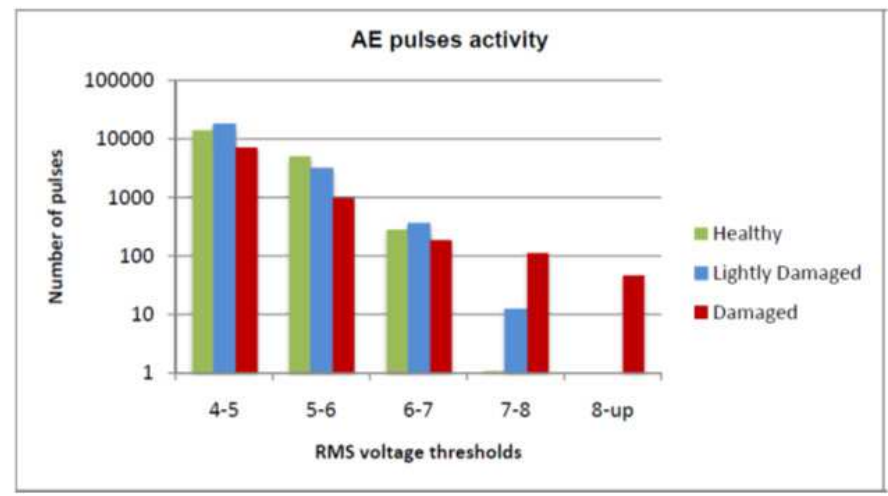

Fig. 9. Acoustic Emission voltage values classification

It is advisable that pulses over $8 \mathrm{~V}$ only appeared during the damaged motor testing while under $7 \mathrm{~V}$ that unit does not show more activity than the healthy and lightly damaged units.

Then, the fuzzy inference system designed uses as reference the number of pulses that surpass the $7 \mathrm{~V}$ value, which is the zone where the distinction of the fault severity of the unit seemed to be more noticeable.

\subsection{Fuzzy inference tool}

The analysis of the actual bearing status was performed using a fuzzy logic inference implementation [11] [12] which maps given inputs to a single output, the different signals acquired are linked to a damage value scaled from 1 to 3 .

The membership functions, like Fig. 10, have been obtained through training and validation process, for each signal under analysis using real motor data. MATLAB "Adaptive neuro-fuzzy inference system" tool has been used for this purpose. Fig. 11 shows the obtained relationship between Vibration and Stator Current RMS values against the Failure Level output for a motor speed of $1500 \mathrm{rpm}$ and a load of $0 \%$. 


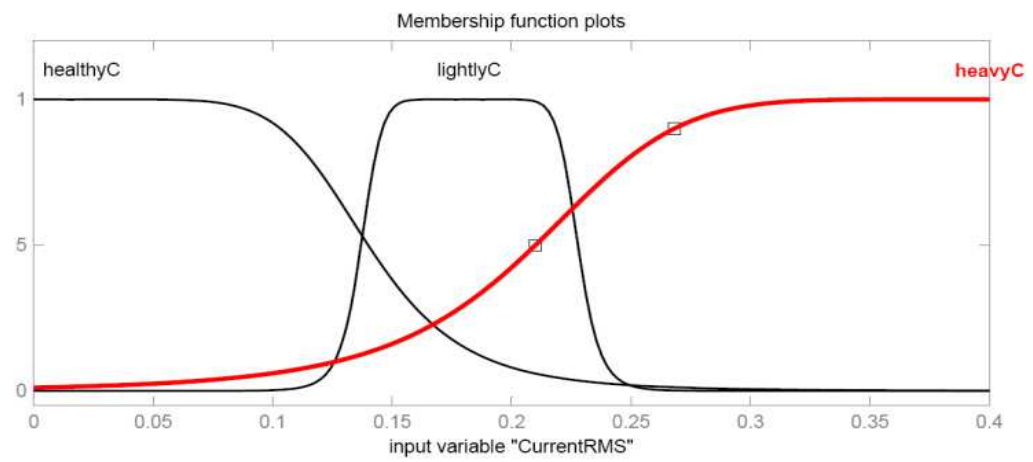

Fig. 10. Membership function plot for Current RMS. (motor speed: $1500 \mathrm{rpm}$, motor load: $0 \%$ )

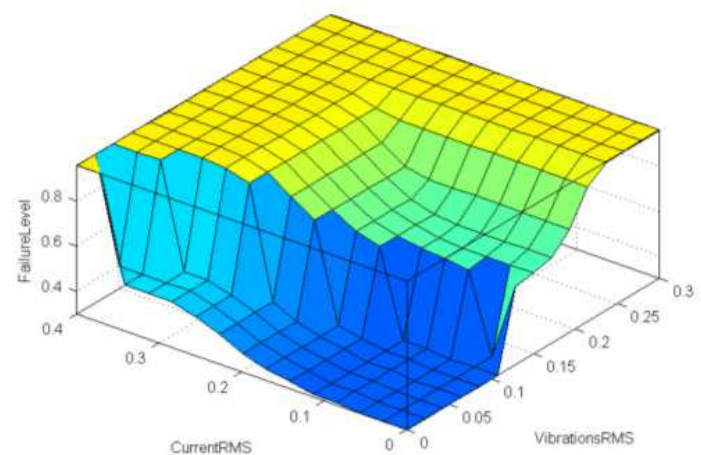

Fig. 11. Plotted surface showing the relationship between the system inputs Vibrations RMS value (g) and Stator Currents RMS value (A) versus the Failure Level output. (Motor speed: $1500 \mathrm{rpm}$, motor load: $0 \%$ )

This process explanation will be properly expanded on the final version of this paper.

To perform the evaluation of the monitoring system designed, fifteen sets of data were collected from the same units and processed. Table 3 summarizes the obtained results.

\begin{tabular}{|l|l|l|}
\hline Unit & Matches & Success \% \\
\hline Healthy & 15 & $100 \%$ \\
Lightly Damaged & 14 & $93,33 \%$ \\
Heavy Damage & 13 & $86,66 \%$ \\
\hline
\end{tabular}

Table 3. System testing results

All healthy data sets were correctly identified, whilst one of the lightly damaged was recognised as a heavily damaged set and two of the heavily damaged sets were identified as lightly damaged ones. The percentage of success was reasonably high and its improvement is still possible if more data sets are used during the system training stage. 


\section{Conclusions}

This chapter gives an overview of a condition monitoring system that uses a multisensory fuzzy inference approach used to detect faults in EMA Systems. The results show that a multivariable design contributes positively to damage monitoring of EMA, being a more solid solution than just using any of the single signals involved..

The results show that a multivariable design contributes positively to damage monitoring of bearings, being a more solid solution than just using any of the single signals involved..

\section{References}

[1] IEEE Motor Reliability Working Group, "Report of large motor reliability survey of industrial and commercial installations," IEEE Transactions on Industrial Applications, vol. IA-21, no. 4. 1986.

[2] Howard, "A Review of Rolling Element Bearing Vibration. Detection, Diagnosis and Prognosis", October 1994.

[3] R. Stack, T. G. Habetler and R. G. Harley, "Fault classification and fault signature production for rolling element bearings in electric machines," Industry Applications, IEEE Transactions on, vol. 40, pp. 735-739, 2004.

[4] M. F. Cabanas, M. G. Melero, G. A. Orcajo, J. M. Cano Rodríguez, Juan Solares Sariego; “Tecnicas para el Mantenimiento y diagnóstico de Máquinas Eléctricas Rotativas", Marcombo, Oviedo, Spain, 1996.

[5] C. M. Riley, B. K. Lin, T. G. Habetler and G. B. Kliman, "Stator current harmonics and their causal vibrations: a preliminary investigation of sensorless vibration monitoring applications," Industry Applications, IEEE Transactions on, vol. 35, pp. 94-99, 1999.

[6] A. Binder, A. Muetze, "Systematical Approach to Bearing Current Evaluation in Speed Drive Systems," ICEM2002.

[7] D. Busse, J. Erdman, R. Kerkman, D. Schlegel, and G. Skibinski, "Characteristics of shaft voltage and bearing currents," Industry Applications Magazine, IEEE, vol. 3, pp. 21-32, 1997.

[8] D. Mba and Raj B. K. N. Rao, "Development of Acoustic Emission Technology forCondition Monitoring and Diagnosis of Rotating Machines: Bearings, Pumps, Gearboxes, Engines, and Rotating Structures," The Shock and Vibration Digest, vol. 38, pp. 3, January 2006. 2006.

[9] N. Tandon, A. Choudhury, A review of the vibration and acoustic measurement methods for detection of defects in rolling element bearings, Tribology International 32 (8) (1999) 469-480.

[10] A. M. Al-Ghamd and D. Mba, "A comparative experimental study on the use of acoustic emission and vibration analysis for bearing defect identification and estimation of defect size," Mechanical Systems and Signal Processing, vol. 20, pp. 15371571, 10. 2006.

[11] X. Lou, K.A. Kenneth and A. Loparo, "Bearing fault diagnosis based on wavelet transform and fuzzy inference", Mechanical Systems and Signal Processing, Volume 18, Issue 5, p. 1077-1095. 
[12] S. Ballal, Z.J. Khan, H. M. Suryawanshi, R.L. Sonolikar, “Adaptive Neural Fuzzy Inference System for the Detection of Inter-Turn Insulation and Bearing Wear Faults in Induction Motor", IEEE Transactions on Industrial Electronics, 2007, Vol.54 Issue 1.

[13] Miettinen, J., Pataniitty, P., "Acoustic Emission in Monitoring Extremely Slowly Rotating Rolling Bearing". Proceedings of COMADEN 1999, 12th International Congress and Exhibition on Condition Monitoring and Diagnostic Engineering Management, July 6-9, 1999, Sunderland, U.K., pp. 289 - 297

[14] Morhain, A. and Mba, D., 2003, "Bearing Defect Diagnosis and Acoustic Emission," Journal of Engineering Tribology, I Mech E, Vol. 217, No. 4, Part J, 257-272

[15] Holroyd, T. J.;"Condition monitoring of very slowly rotating machinery using AE techniques", COMADEN 2001, Manchester, 4th of September, 2001, Manchester, 8p

[16] Singh, A., Houser, D. R., and Vijayakar, S., 1999, "Detecting Gear Tooth Breakage Using Acoustic Emission: A Feasibility and Sensor Placement Study," Journal of Mechanical Design, Vol. 121, 587-593.

[17] Miyachika, K., Zheng, Y., Tsubokura, K., Oda, S., Kanayama, Y., Koide, T., Namba, C., and Hayashi, T., 2002, "Acoustic Emission of Bending Fatigue Process of Supercarburized Spur Gear Teeth," Progress in Acoustic Emission XI, The Japanese Society for NDI, pp. 304-310

[18] Siores, E. and Negro, A. A., 1997, “Condition Monitoring of a Gear Box sing Acoustic Emission Testing," Material Evaluation, Vol. 55, No. 2, 183-187

[19] Badi, M. N. M., Engin, S. N., and Schonfeld, D., 1996, "Fault Classification of a Model Drive Line Using Time Domain Data," in Proceedings of COMADEM 1996, Sheffield, UK, pp. 43-50

[20] Al-Balushi, K. R. and Samanta, B., 2000, "Gear Fault Diagnostics Using Wavelets and Artificial Neural Networks," in Proceedings of COMADEM 2000, Houston, TX, pp. 1001-1010 


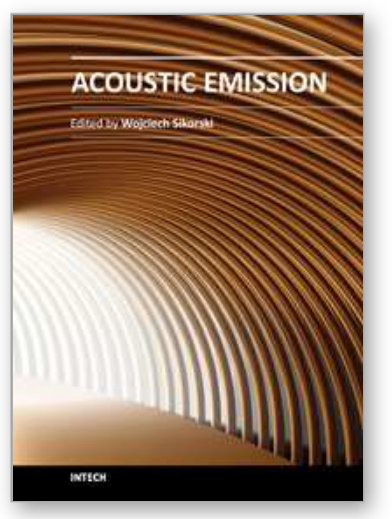

\author{
Acoustic Emission \\ Edited by Dr. Wojciech Sikorski
}

ISBN 978-953-51-0056-0

Hard cover, 398 pages

Publisher InTech

Published online 02, March, 2012

Published in print edition March, 2012

Acoustic emission (AE) is one of the most important non-destructive testing (NDT) methods for materials, constructions and machines. Acoustic emission is defined as the transient elastic energy that is spontaneously released when materials undergo deformation, fracture, or both. This interdisciplinary book consists of 17 chapters, which widely discuss the most important applications of AE method as machinery and civil structures condition assessment, fatigue and fracture materials research, detection of material defects and deformations, diagnostics of cutting tools and machine cutting process, monitoring of stress and ageing in materials, research, chemical reactions and phase transitions research, and earthquake prediction.

\title{
How to reference
}

In order to correctly reference this scholarly work, feel free to copy and paste the following:

Jordi Cusidó i Roura, Miguel Delgado Prieto, Jose Luis Romeral Martínez (2012). EMA Fault Detection Using Fuzzy Inference Tools, Acoustic Emission, Dr. Wojciech Sikorski (Ed.), ISBN: 978-953-51-0056-0, InTech, Available from: http://www.intechopen.com/books/acoustic-emission/ema-fault-detection-using-fuzzyinference-tools

\section{INTECH}

open science | open minds

\section{InTech Europe}

University Campus STeP Ri Slavka Krautzeka 83/A 51000 Rijeka, Croatia Phone: +385 (51) 770447

Fax: +385 (51) 686166 www.intechopen.com

\section{InTech China}

Unit 405, Office Block, Hotel Equatorial Shanghai No.65, Yan An Road (West), Shanghai, 200040, China 中国上海市延安西路65号上海国际贵都大饭店办公楼405单元 Phone: +86-21-62489820

Fax: +86-21-62489821 